\title{
The new age of sudomotor function testing: a sensitive and specific biomarker for diagnosis, estimation of severity, monitoring progression, and regression in response to intervention
}

\section{OPEN ACCESS}

Edited by:

Soroku Yagihashi,

Hirosaki University Graduate School

of Medicine, Japan

Reviewed by:

Julianne Toohey,

University of California Irvine Medical

Center, USA

Ivan Tkac,

Pavol Jozef Šafárik University,

Slovakia

${ }^{*}$ Correspondence:

Aaron I. Vinik,

Division of Endocrinology and Metabolism, Department of Medicine, Strelitz Diabetes and Neuroendocrine Center, Eastern Virginia Medical

School, 855 West Brambleton Avenue, Norfolk, VA 23510, USA vinikai@evms.edu

Specialty section:

This article was submitted to Diabetes, a section of the journal

Frontiers in Endocrinology

Received: 23 March 2015

Accepted: 23 May 2015

Published: 11 June 2015

Citation:

Vinik Al, Nevoret M-L and Casellini C

(2015) The new age of sudomotor function testing: a sensitive and specific biomarker for diagnosis, estimation of severity, monitoring progression, and regression in response to intervention. Front. Endocrinol. 6:94. doi: 10.3389/fendo.2015.00094

\section{Aaron I. Vinik ${ }^{1 *}$, Marie-Laure Nevoret ${ }^{2}$ and Carolina Casellini ${ }^{1}$}

${ }^{1}$ Division of Endocrinology and Metabolism, Department of Medicine, Strelitz Diabetes and Neuroendocrine Center, Eastern Virginia Medical School, Norfolk, VA, USA, ${ }^{2}$ Impeto Medical Inc., San Diego, CA, USA

Sudorimetry technology has evolved dramatically, as a rapid, non-invasive, robust, and accurate biomarker for small fibers that can easily be integrated into clinical practice. Though skin biopsy with quantitation of intraepidermal nerve fiber density is still currently recognized as the gold standard, sudorimetry may yield diagnostic information not only on autonomic dysfunction but also enhance the assessment of the small somatosensory nerves, disease detection, progression, and response to therapy. Sudorimetry can be assessed using Sudoscan ${ }^{\mathrm{TM}}$, which measures electrochemical skin conductance (ESC) of hands and feet. It is based on different electrochemical principles (reverse iontophoresis and chronoamperometry) to measure sudomotor function than prior technologies, affording it a much more practical and precise performance profile for routine clinical use with potential as a research tool. Small nerve fiber dysfunction has been found to occur early in metabolic syndrome and diabetes and may also be the only neurological manifestation in small fiber neuropathies, beneath the detection limits of traditional nerve function tests. Test results are robust, accomplished within minutes, require little technical training and no calculations, since established norms have been provided for the effects of age, gender, and ethnicity. Sudomotor testing has been greatly under-utilized in the past, restricted to specialized centers capable of handling the technically demanding and expensive technology. Yet, evaluation of autonomic and somatic nerve function has been shown to be one of the best estimates of cardiovascular risk. Evaluation of sweating has the appeal of quantifiable non-invasive determination of the integrity of the peripheral autonomic nervous system, and can now be accomplished rapidly at point of care clinics with the determination of ESC, allowing intervention for morbid complications prior to permanent structural nerve damage. We review here sudomotor function testing technology, the research evidence accumulated supporting the clinical utility of measuring ESC, the medical applications of sudorimetry now available to physicians with this device, and clinical vignettes illustrating its use in the clinical decision-making process.

Keywords: sudomotor, sudorimetry, small nerve fiber, peripheral neuropathy, autonomic neuropathy 
Evaluation of autonomic and somatic nerve function has now been shown to be one of the most important predictors of cardiovascular risk (1-6). While there are bedside means of evaluation of the integrity of the somatic nervous system (NIS-LL $(7,8)$, UENS (9), and MNSI (10), these are imprecise and the use of gold standard measures such as nerve conduction studies are burdensome, time consuming, and do not capture small nerve fiber function (11-13). Clearly a simple, rapid, and precise means of quantification of both large and small fiber function would greatly enhance the capacity to capture all the elements of peripheral and autonomic neuropathy. Autonomic function tests have been extraordinarily useful in diagnosing, treating, and better understanding of the complex mechanisms behind disturbances in balance of the function of the two domains of the autonomic nervous system, namely sympathetic and parasympathetic (14). The ability to capture time and frequency domains of heart rate variability (14), as well as baroreceptor sensitivity, has facilitated the evaluation of balance between the two arms of the autonomic nervous system, providing information on functional changes prior to the development of permanent structural damage and allowing the use of rebalancing therapeutic options (15). Small unmyelinated $\mathrm{C}$ and $\mathrm{A} \delta$ fibers in the periphery subserve somatic and autonomic nerve functions such as warm, cold, and pain perception, as well as innervating sweat glands. The gold standard for their evaluation has been skin biopsy and quantification of intraepidermal nerve fiber density, an invasive procedure $(16,17)$. On the other hand, the evaluation of sweating has the appeal of quantifiable non-invasive determination of the integrity of the peripheral autonomic nervous system. However, activation of sweat glands is complex and both sympathetic and parasympathetic innervation contribute to normal sweat gland function (18). A variety of techniques have capitalized on quantifying sweating (19) or the innervation of sweat glands $(20,21)$ to capture the impact of disordered regulation on structure and function of sweat glands as surrogates for the underlying somatic and autonomic dysfunction.

Sudorimetry - or sudomotor function testing - the science of measuring the function of sweat gland innervation, is unique among the autonomic function tests in that it evaluates the peripheral sympathetic system but relies principally on cholinergic post-ganglionic neurotransmission. Recently, a newer sudomotor function technology (Sudoscan) has become available and adds a new tool to test at point of care in the clinic when autonomic testing had been previously restricted to specialized neurological laboratories. With an aging, increasingly obese population with diabetes and prediabetes, disorders that manifest autonomic dysfunctions are becoming common and sudorimetry may allow earlier intervention for these morbid complications.

\section{Sudomotor Function Technology: The Why and the How}

Sweat glands being present at the skin surface, their stimulation and measured response have been extensively utilized to assess disorders of the autonomic system non-invasively, specifically the peripheral sympathetic system. Sudomotor nerves are Cfibers, thin unmyelinated, or poorly myelinated with primarily cholinergic neurotransmission, wherein the neurotransmitter at the ganglion is acetylcholine, the principal neurotransmitter of the parasympathetic nervous system. However, epinephrine, norepinephrine, vasoactive intestinal peptide (VIP), atrial natriuretic peptide, calcitonin gene related polypeptide (CGRP), galanin, ATP, and substance $P$ have also been localized to peri-glandular nerves (22). The nerve fibers are structurally similar to small nerve fibers of warm and cold thermal perception, and hence prone to damage by the same metabolic insults (Figure 1).

Small nerve fiber dysfunction has been found to occur early in metabolic syndrome and diabetes $(23,24)$, and may also be the only neurological manifestation in small fiber neuropathies (25, 26). Apart from skin biopsy, measuring small nerve fiber function has been limited to assessment of symptoms and quantitative sensory testing for warm, cold, and pain thresholds, which lack the precision required for a practical clinical profile or use in the research arena.

The unique qualities of sudomotor function tests are that, in clinical application, they may yield diagnostic information not only of autonomic dysfunction but also enhance the assessment of the small somatosensory nerves $(27,28)$. To date, however, most sudomotor function testing procedures were not accessible for widespread use but rather confined to specialized autonomic

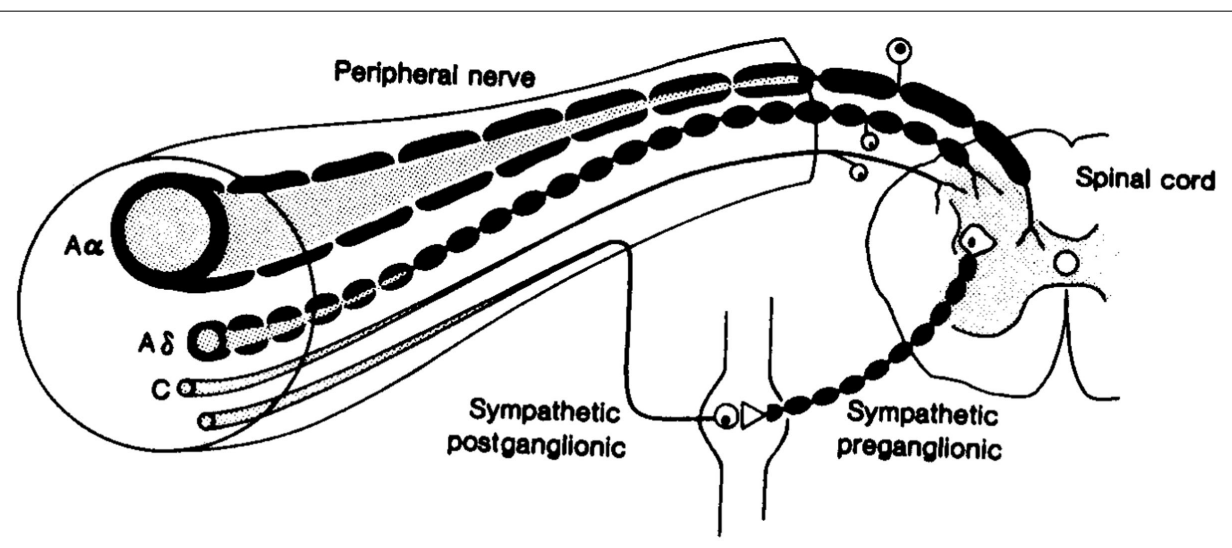

FIGURE 1 | Fibers of the peripheral nervous system: note the afferent and efferent connections among the small A $\delta$ and $C$ fibers (71). 
labs. Tests using iodine and starch (thermoregulatory sweat test), the Neuropad $(29,30)$, or iontophoretic stimulation and quantification of sweating are either time consuming, technically demanding, or lack sensitivity, specificity, or reproducibility to be of practical use (31-33). Furthermore, they were prone to both environmental and patient-specific confounders like room temperature, medications, food, and habituation. Excellent reviews on sudomotor function tests can be read elsewhere (19).

In contrast, Sudoscan ${ }^{\mathrm{TM}}$ is based on different electrochemical principles (reverse iontophoresis and chronoamperometry) to measure sudomotor function than prior technologies, affording it a much more practical and precise performance profile for routine clinical use with potential as a research tool. The device consists of a simple desktop computer connected to two sets of large surface stainless steel electrodes: two for application of the palms, and two for the soles. The patient places both hands and feet simultaneously on the designated electrodes and a painless scanning process ensues over the course of $2-3 \mathrm{~min}$. A low DC voltage is incrementally applied to the electrodes, ranging from 1 to $4 \mathrm{~V}$, with the left and right electrodes serving alternatively as cathode and anode. At voltages under $10 \mathrm{~V}$, the thick stratum corneum is electrically insulating; the sweat glands, however, consist of a cellular bilayer and therefore can transmit electrically charged ions to the skin surface and the electrodes (reverse iontophoresis). The current of sweat chloride ions generated in response to the incremental voltage applied can be quantified and reflects the function of the sweat gland, and hence its $\mathrm{C}$ fiber innervation. This chloride ion current is reported as electrochemical skin conductance (ESC) - the inverse of resistance - measured in microSiemens $(\mu \mathrm{S})$.

The palms and soles are specifically assessed due to their very high density of sweat glands and the frequency of small nerve degeneration occurring in a length-dependent fashion; i.e., affecting the distal-most nerve endings first. Also, by alternating the left and right extremities as anode and cathode, each extremity is evaluated separately during the $3 \mathrm{~min}$ scan, and asymmetry between the extremities can be calculated by the device.

\section{Clinical Diagnostic Evaluation Using ESC: Assessment of Somatic and Autonomic Nerve Dysfunction}

The clinical diagnostic accuracy of Sudoscan ${ }^{\mathrm{TM}}$ has been evaluated for diabetic peripheral sensorimotor polyneuropathy (DPN), peripheral small fiber neuropathy, and autonomic neuropathy against other standard methods.

Casellini et al. (34) examined 83 type 1 and 2 diabetic patients, both with and without DPN, and compared them to 210 healthy controls (HC). Diabetic patients with DPN had significantly worse ESCs of both feet and hands than patients without DPN and HC [56.3 \pm 3 vs. $75.9 \pm 5.5$ and $84.4 \pm 0.9(p<0.0001)$ for feet and $51.9 \pm 2.4$ vs. $67.5 \pm 4.3$ and $73.1 \pm 0.8(p<0.0001)$ for hands]. Somewhat surprisingly, ESCs correlated significantly with clinical neuropathy scores of sensory, motor, and reflex function; somatic (quantitative sensory testing and nerve conduction studies) and autonomic (quantitative autonomic function testing) measures of DPN suggesting that the measure captures both somatic and

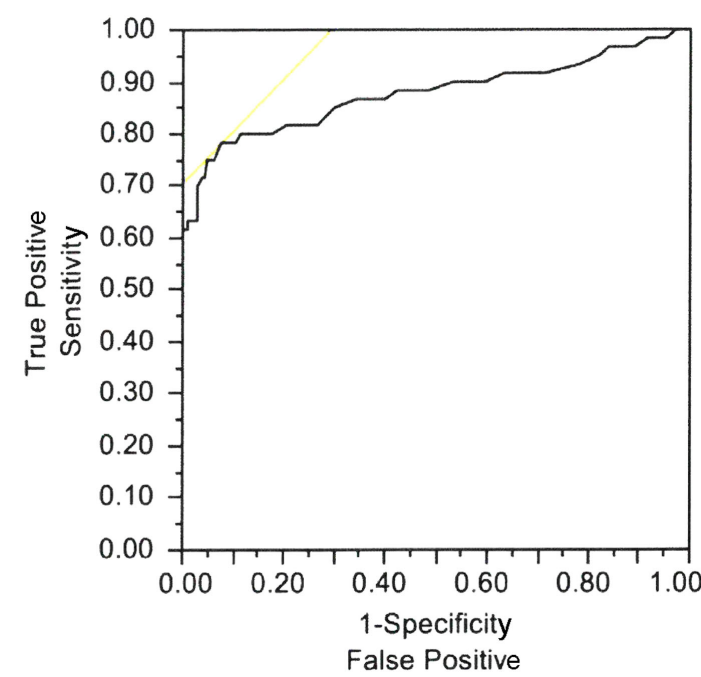

FIGURE 2 | Electrochemical skin conductance of feet receiver-operator characteristic (ROC) curve to reflect diabetic neuropathy. Area under the curve $=0.8755, p<0.0001$ (34).

autonomic nerve function. Using a Neuropathy Impairment Score of the Lower Limb (NIS-LL) $>2$ as the gold standard for the diagnosis of neuropathy, the sensitivity and specificity of ESC for the diagnosis of DPN were 78 and $92 \%$, respectively, for feet, with an ROC area under the curve of $0.8755(p<0.0001)$ (Figure 2). Table 1 compares ESC results to vibration detection threshold (VDT) and sural amplitude and suggests that Sudoscan is a moderately sensitive but highly specific tool to detect DPN. The investigators further determined the correlations between sudorimetry and somatic and autonomic function as shown in 48 type 2 diabetic patients (Table 2). There were strong correlations between ESC and both somatic (sensory and motor) and autonomic functions; sudorimetry scores were also able to separate painful from non-painful DPN.

In this cohort, sweat gland size and morphology were not available. There is evidence that sweat glands and sweat gland duct diameter may be smaller in patients with DPN $(35,36)$; one likely etiology is the thickened endothelial basement membranes of feeding capillaries resulting in microvascular damage of cutaneous structures. However, the contribution of these morphological abnormalities to diabetic sudomotor dysfunction is not known.

Distal symmetric polyneuropathy (DSP) presents with small fiber-predominant dysfunction; early detection currently relies on skin biopsy with quantification of intraepidermal nerve fiber density (IENFD). Smith et al. (9) studied 55 patients with suspected DSP (idiopathic or diabetes-related) and $42 \mathrm{HC}$ to evaluate the diagnostic performance of ESC. Using an abnormal Utah Early Neuropathy Score (UENS) $\geq 4$ as the diagnostic gold standard, feet and hands ESC were significantly lower in DSP subjects than $\mathrm{HC}$, regardless of the etiology of DSP: $64 \pm 22$ vs. $76 \pm 14 \mu \mathrm{S}$, and $58 \pm 19$ vs. $66 \pm 18 \mu$ S, respectively. More importantly, ESC and IENFD had similar diagnostic performance in detecting DSP, with a ROC area under the curve of 0.761 and 0.752 , respectively (Figure 3). Mirroring the findings of Casellini et al., feet ESC had a 
TABLE 1 | Diagnostic efficiency of feet and hands electrochemical skin conductance to reflect diabetic neuropathy (Neurologic Impairment Score - lower limbs) (34).

\begin{tabular}{|c|c|c|c|c|c|c|c|}
\hline & Criterion $^{a}$ & Sensitivity & Specificity & $+\mathbf{L R}$ & $-L R$ & $+\mathbf{P V}$ & $-\mathbf{P V}$ \\
\hline Hands ESC & 64 & 78.33 & 85.71 & 5.48 & 0.25 & 61.04 & 93.26 \\
\hline Feet ESC & 77 & 78.34 & 92.38 & 10.28 & 0.23 & 74.6 & 93.72 \\
\hline Total NIS-LL & 1.5 & 76.67 & 85.71 & 5.37 & 0.27 & 95.83 & 46.15 \\
\hline
\end{tabular}

${ }^{a}$ Criterion corresponding with highest Youden index.

ESC, electrochemical skin conductance; $+L R$, positive likelihood ratio; $-L R$, negative likelihood ratio; NIS-LL, Neurologic Impairment Score-Lower Legs; +PV, positive predictive value; $-P V$, negative predictive value.

very high negative predictive value (83\%) and significantly correlated with both symptoms and signs assessed using the Michigan Neuropathy Screening Instrument (MNSI) and the Utah early neuropathy symptom scale(UENS). Also, quantitative sudomotor axon reflex testing (QSART) at the foot and feet ESC were correlated, but only moderately $(0.348, p<0.015)$; the authors attributed this observation to the large standard deviation in the QSART data, a reflection of variability in sweat volume produced. An alternate explanation is that $\mathrm{Cl}$ ion transport may reflect functions other than sweating alone (9).

Yajnik and colleagues (37) investigated DPN and autonomic neuropathy in 265 type 2 diabetic patients using ESC measurements, MNSI, and vibration perception threshold (VPT). Again, feet ESC were significantly correlated with MNSI Part A (symptoms, $p<0.05)$ and Part B (physical examination, $p<0.001$ ), and VPT $(p<0.001)$. Gin et al. (38) similarly compared ESC to VPT in the diagnosis of DPN among 142 diabetic (67\% type 2) individuals. The correlation coefficient between foot ESC and VPT was $-0.45(p<0.0001)$. VPT and ESC also correlated with retinopathy status $[r=0.52$ (SD 0.07) and -0.52 (SD 0.07), respectively; $p<0.0001$ ] and with creatinine clearance $(p=0.003)$ in the Modification of Diet in Renal Disease (MDRD).

As in the study by Casellini and collaborators, a number of projects have shown that ESC measurement may be a simple tool for early identification of autonomic neuropathy, and may be useful in screening for sub-clinical cardiac autonomic neuropathy (CAN). Calvet et al. (39) in 232 diabetic individuals showed a high correlation between CAN risk score (calculated from ESC) and the low frequency (LF) component, a measure of sympathetic and baroreceptor function (40), during moderate activity $(r=0.47$, $p<0.001$ ). When taking the LF power component during moderate activity $<90 \mathrm{~ms}^{2}$ as a reference value, the ROC area under the curve for the CAN risk score was 0.77 , with a sensitivity and specificity of 83 and $63 \%$, respectively.

Below are summarized some of the major studies completed using ESC measurement in a clinical diagnostic capacity (Table 3).

\section{Validation of ESC Robustness}

For ESC measurement to be clinically meaningful, widely applicable thresholds for normal and abnormal sudomotor function had to be determined, and high reproducibility of results had to be demonstrated. One of the weaknesses of many sudomotor function tests has been their wide range of normal values (QSART) and their sensitivity to temperature, age, medications, and food. Habituation (decreases in result amplitude with repeated testing) is a particular problem with sympathetic skin response.
Initially, a large cohort of healthy subjects (432 females, 177 males; age >20-years-old; without known neuropathy, diabetes, or chronic medical condition; BMI $<25$ ) were tested using Sudoscan $^{\mathrm{TM}}$ to determine population normative values. The results of this study are depicted in Table 4 and indicate the following: (1) there is almost no drop-off in normal sudomotor function from age 21 to 80 ; (2) results are not significantly different between the sexes; and (3) a threshold of $60 \mu \mathrm{S}$ for hands and feet does not result in a significant number of false positives (healthy subjects being diagnosed with dysautonomia). Only in the eighth decade, do mean ESC values decrease slightly (eighth vs. third decade feet ESC: $75.5 \pm 9.3$ vs. $83.9 \pm 5.8 \mu \mathrm{S}$ for women, respectively; $76.0 \pm 9.4$ vs. $81.7 \pm 7.6 \mu \mathrm{S}$ for men, respectively).

Cohorts of diabetic patients, both with and without DPN, then underwent ESC testing by Gin and Yajnik $(37,38)$; these studies indicated that a threshold of $60 \mu \mathrm{S}$ clearly separated normal ("green" zone) from abnormal ("yellow" and "red" zones) sudomotor function for both the hands and feet. A second threshold of $40 \mu \mathrm{S}$ denoted the level below which sudomotor function was severely impaired ("red" zone) and correlated closely with advanced peripheral neuropathy and attendant complications, e.g., foot ulceration $(34,37,38)$.

Three critical studies were then completed in the US $(9,34,43)$ and led to further refinement of ESC thresholds by comparing ESC scores against multiple validated DPN tools. Results of these studies demonstrated that: (1) the initial 40 and $60 \mu \mathrm{S}$ thresholds best applied to Asian populations; (2) optimal sensitivity of ESC testing in Caucasians required raising the foot ESC threshold to $70 \mu \mathrm{S}$; and (3) African Americans had unique sudomotor physiology requiring specific ESC thresholds for both hands and feet. Though threshold refinement by ethnic background has not yet been clinically validated for all populations, using the adjustments depicted in Table 5 below is already allowing much stronger accuracy of ESC result interpretation and clinically meaningful information for the physician.

Reproducibility testing was performed under various stress scenarios as well as normal conditions.

\section{Effect of Chronic Disease}

Electrochemical skin conductance measurements were assessed twice on the same day in patients with at least one cardiovascular risk and in patients with diabetes. Results were compared using a Bland-Altman plot. The coefficient of variation was $7 \%$ in hands and $5 \%$ in feet in patients with cardiovascular risk and $15 \%$ in hands and $7 \%$ in feet in patients with diabetes in whom the coefficient of variation for glycemia between the two measurements was $32 \%$. 
TABLE 2 | Spearman's $\rho$ ranked correlations of feet ESC with clinical, somatic, and autonomic measures of neuropathy in $\mathbf{4 8}$ patients with type 2 diabetes (34).

\begin{tabular}{|c|c|c|c|}
\hline & Feet ESC & Spearman $\rho$ & $p$-Value \\
\hline \multicolumn{4}{|c|}{ CLINICAL NEUROPATHY SCORES } \\
\hline DM duration & Feet ESC & -0.4904 & 0.0005 \\
\hline $\begin{array}{l}\text { Neurologic symptom } \\
\text { score (NSS) }\end{array}$ & Feet ESC & -0.4437 & 0.0016 \\
\hline Sensory score & Feet ESC & -0.6313 & $<0.0001$ \\
\hline Motor score & Feet ESC & -0.5499 & $<0.0001$ \\
\hline $\begin{array}{l}\text { Total neuropathy score } \\
\text { (TNS) }\end{array}$ & Feet ESC & -0.5851 & $<0.0001$ \\
\hline Total NIS-LL motor & Feet ESC & -0.6687 & $<0.0001$ \\
\hline Total NIS-LL sensory & Feet ESC & -0.6672 & $<0.0001$ \\
\hline Total NIS-LL score & Feet ESC & -0.6160 & $<0.0001$ \\
\hline \multicolumn{4}{|c|}{ AUTONOMIC FUNCTION MEASURES (QAFTS) ${ }^{a}$} \\
\hline $\begin{array}{l}\text { Expiration/inspiration ratio } \\
(E / /)\end{array}$ & Feet ESC & 0.4858 & 0.0005 \\
\hline Valsalva ratio & Feet ESC & 0.3182 & 0.0275 \\
\hline $\begin{array}{l}\text { Deep breathing total } \\
\text { spectral power (TSP) }\end{array}$ & Feet ESC & 0.4745 & 0.0008 \\
\hline Deep breathing sdNN & Feet ESC & 0.4252 & 0.0029 \\
\hline Deep breathing rmsSD & Feet ESC & 0.3778 & 0.0088 \\
\hline Valsalva TSP & Feet ESC & 0.4320 & 0.0024 \\
\hline Valsalva sdNN & Feet ESC & 0.3708 & 0.0103 \\
\hline Valsalva rmsSD & Feet ESC & 0.3026 & 0.0387 \\
\hline \multicolumn{4}{|c|}{ QUANTITATIVE SENSORY TESTING (QSTS) } \\
\hline $\begin{array}{l}\text { Great toe vibration } \\
\text { detection }\end{array}$ & Feet ESC & -0.5003 & 0.0004 \\
\hline $\begin{array}{l}\text { Great toe pressure } \\
\text { (monofilament) }\end{array}$ & Feet ESC & -0.6250 & $<0.0001$ \\
\hline Great toe cold perception & Feet ESC & -0.4625 & 0.0012 \\
\hline $\begin{array}{l}\text { Great toe warm } \\
\text { perception }\end{array}$ & Feet ESC & -0.4857 & 0.0006 \\
\hline \multicolumn{4}{|l|}{ PAIN SCORES (NRS) } \\
\hline $\begin{array}{l}\text { Great toe symptomatic } \\
\text { pain }\end{array}$ & Feet ESC & -0.4397 & 0.0022 \\
\hline Great toe mechanical pain & Feet ESC & -0.3508 & 0.0168 \\
\hline \multicolumn{4}{|c|}{ NERVE CONDUCTION STUDIES (NCS) } \\
\hline $\begin{array}{l}\text { Peroneal ankle amplitude } \\
\text { (Amp) }\end{array}$ & Feet ESC & 0.4889 & 0.0005 \\
\hline Peroneal below fibula Amp & Feet ESC & 0.5867 & $<0.0001$ \\
\hline $\begin{array}{l}\text { Peroneal below fibula } \\
\text { conduction velocity (CV) }\end{array}$ & Feet ESC & 0.4724 & 0.0008 \\
\hline Peroneal above fibula Amp & Feet ESC & 0.5496 & $<0.0001$ \\
\hline Peroneal above fibula CV & Feet ESC & 0.4381 & 0.0021 \\
\hline Sural Amp & Feet ESC & 0.5234 & 0.0043 \\
\hline Sural CV & Feet ESC & 0.5503 & 0.0024 \\
\hline \multicolumn{4}{|l|}{ LABORATORY VARIABLES } \\
\hline $\begin{array}{l}\text { Urine albumin/creatinine } \\
\text { ratio }\end{array}$ & Feet ESC & -0.3724 & 0.0196 \\
\hline
\end{tabular}

${ }^{\text {a Data a }}$ are log-transformed.

\#Spearman's $\rho$ rank test was applied.

$D M$, diabetes mellitus; ESC, electrochemical skin conductance; NIS-LL, neuropathy impairment score of lower legs; NRS, numeric rating score; rmsSD, root mean square of the difference of successive R-R intervals; sdnn, sample difference of the beat to beat (NN) variability.

\section{Effect of Glycaemia}

As this technology is frequently applied to pre-diabetic or diabetic patients with potentially high glycemic variations, ESC measurements were performed twice in 12 patients, once when blood

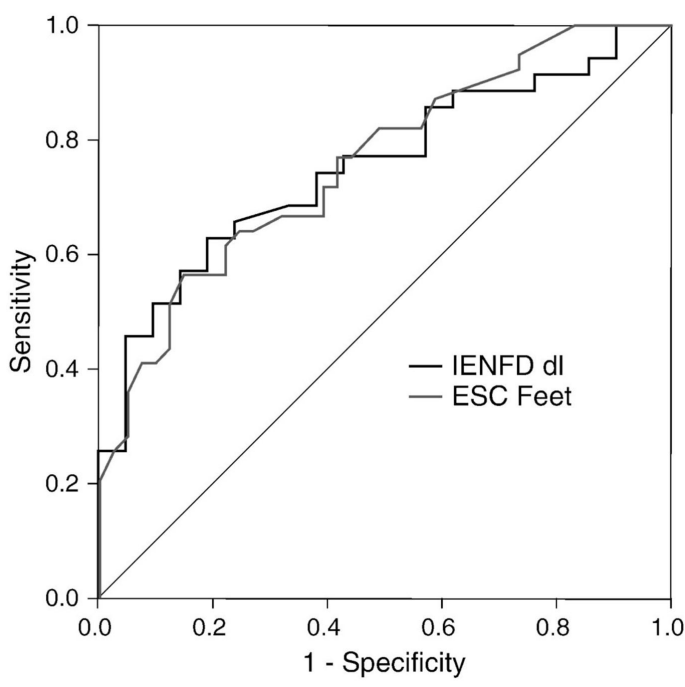

FIGURE 3 | Receiver operating characteristics (ROC) curves for feet ESC and skin biopsy using abnormal Utah Early Neuropathy Score (UENS) as the gold standard. Area under the curve (AUC) for ESC feet and intraepidermal nerve fiber density (IENFD) were similar $(0.761,0.752$,

respectively) (9).

glucose levels were $\geq 325 \mathrm{mg} / \mathrm{dL}$ and once when normoglycemic. The coefficient of variation between the two sets of measurements from a Bland-Altman plot was $10 \%$ in the feet. This is not unexpected as hyperglycemia induces a state of hyperosmotic dehydration. In hyperosmolar hyperglycemic non-ketotic syndrome, there is an absence of sweating in an attempt to conserve water, probably with diversion of blood from cutaneous microvascular beds. It may be that the ESC test, despite supra-physiological stimulation of the sweat glands, is unable to overcome the body's conservation mechanism, leading to changes in ESC results during hyperglycemia. Just as the stomach is paralyzed by hyperglycemia and gastric emptying should only be measured when blood glucose levels are near normal $(<250 \mathrm{mg} / \mathrm{dL})$ so should sudorimetry strive to be examined only when the blood glucose is near normal.

\section{Effect of Exercise}

As exercise could influence sweat function, measurements were taken before and after an ergonomic bicycle exercise test at a level of $87 \%$ of maximum heart rate. ESC before and after measurements had a coefficient of variation of $4 \%$ in the feet and $8 \%$ in the hands.

\section{Effect of the Device}

Three measurements were performed in 21 patients using three different devices. There was no significant difference between the three measurements, and the paired Spearman test evidenced a coefficient of correlation higher than 0.96 for each comparison $(p<0.0001)(44)$.

\section{Sudomotor Function and Aging}

It is now well accepted that important changes to the autonomic nervous system occur with aging, leading not only to increased 
TABLE 3 | Feet ESC diagnostic accuracy vs. established clinical tools

\begin{tabular}{|c|c|c|c|c|c|c|}
\hline Study & Diagnostic variable & Comparison & Sensitivity (\%) & Specificity (\%) & PPV (\%) & NPV (\%) \\
\hline Casellini (34) & DPN & NIS-LL & 78 & 92 & 74 & 93 \\
\hline Smith (9) & Distal symmetric polyneuropathy & UENS & 77 & 67 & 59 & 83 \\
\hline Yajnik (37) & DPN & VPT & 73 & 62 & $\mathrm{~N} / \mathrm{A}$ & N/A \\
\hline Eranki (41) & DPN & VPT & 82 & 55 & $\mathrm{~N} / \mathrm{A}$ & $\mathrm{N} / \mathrm{A}$ \\
\hline Calvet (39) & CAN - diabetes & CARTs & 83 & 63 & $\mathrm{~N} / \mathrm{A}$ & $\mathrm{N} / \mathrm{A}$ \\
\hline Ozaki (42) & Diabetic kidney disease & eGFR, ACR & 94 & 78 & 81 & 93 \\
\hline
\end{tabular}

ACR, albumin creatinine ratio; CAN, cardiac autonomic neuropathy; CARTs, cardiac autonomic reflex tests; DPN, diabetic peripheral neuropathy; eGFR, estimated glomerular filtration rate; NIS-LL, Neuropathy Impairment Score - Lower Limbs; PPV, positive predictive value; NPV, negative predictive value; UENS, Utah Early Neuropathy Score; VPT, vibration perception threshold.

TABLE 4 | Effects of age and gender on ESC measurements in 609 normal subjects.

\begin{tabular}{|c|c|c|c|c|c|c|c|}
\hline & \multicolumn{7}{|c|}{ Age (years) ${ }^{a}$} \\
\hline & Overall & $21-30$ & $31-40$ & $41-50$ & $51-60$ & $61-70$ & $71-80$ \\
\hline \multicolumn{8}{|l|}{ FEMALE } \\
\hline ESC hands & $(n=432)$ & $(n=29)$ & $(n=73)$ & $(n=136)$ & $(n=143)$ & $(n=28)$ & $(n=23)$ \\
\hline Mean \pm SD & $74.0 \pm 8.7$ & $74.7 \pm 9.6$ & $75.9 \pm 8.8$ & $74.0 \pm 8.4$ & $73.8 \pm 8.3$ & $71.1 \pm 10.1$ & $71.0 \pm 9.6$ \\
\hline Median & 75.0 & 75.0 & 77.0 & 74.5 & 75.0 & 70.3 & 71.5 \\
\hline 80th percentile interval & $61.5-85.0$ & $62.6-86.2$ & $62.6-87.0$ & $62.0-85.0$ & $62.0-85.0$ & 58.9-83.6 & $55.9-81.4$ \\
\hline \multicolumn{8}{|l|}{ ESC feet } \\
\hline Mean $\pm S D$ & $82.8 \pm 5.8$ & $83.9 \pm 5.8$ & $84.2 \pm 4.8$ & $83.1 \pm 5.2$ & $82.7 \pm 5.6$ & $82.2 \pm 4.2$ & $75.5 \pm 9.3$ \\
\hline Median & 83.5 & 84.5 & 85.0 & 84.5 & 83.0 & 83.0 & 79.0 \\
\hline 80th percentile interval & $76.0-89.0$ & $79.1-90.0$ & $77.1-89.5$ & $76.5-89.0$ & $75.5-89.5$ & $76.7-86.5$ & $65.1-86.7$ \\
\hline \multicolumn{8}{|l|}{ MALE } \\
\hline ESC hands & $(n=177)$ & $(n=46)$ & $(n=30)$ & $(n=33)$ & $(n=42)$ & $(n=10)$ & $(n=16)$ \\
\hline Mean \pm SD & $74.9 \pm 9.6$ & $76.0 \pm 10.1$ & $77.4 \pm 6.6$ & $75.2 \pm 10.7$ & $75.8 \pm 7.7$ & $72.3 \pm 11.6$ & $66.2 \pm 10.0$ \\
\hline Median & 76.5 & 77.5 & 78.3 & 78.0 & 76.3 & 75.0 & 68.0 \\
\hline 80th percentile interval & $62.5-86.5$ & 63.0-87.5 & $69.1-85.6$ & $61.1-87.9$ & $66.7-86.4$ & $56.1-85.6$ & $52.5-78.3$ \\
\hline \multicolumn{8}{|l|}{ ESC feet } \\
\hline Mean $\pm S D$ & $81.5 \pm 7.0$ & $81.7 \pm 7.6$ & $81.2 \pm 5.6$ & $81.0 \pm 7.1$ & $84.0 \pm 5.7$ & $81.5 \pm 4.4$ & $76.0 \pm 9.4$ \\
\hline Median & 82.5 & 82.5 & 81.0 & 83.0 & 84.5 & 81.8 & 79.3 \\
\hline 80th percentile interval & 73.0-89.5 & 73.8-90.5 & $75.0-88.2$ & 71.3-89.3 & $76.1-90.0$ & $76.7-86.2$ & $67.5-83.5$ \\
\hline
\end{tabular}

alnternal data provided by Impeto Medical, Inc.

TABLE 5 | Electrochemical skin conductance (ESC) zones for normal sudomotor function (green), moderate sudomotor dysfunction (yellow), and severe sudomotor dysfunction (red) as defined by racial background.

\begin{tabular}{|c|c|c|c|c|c|c|}
\hline Race & $\begin{array}{c}\text { Hands ESC } \\
\text { red zone }\end{array}$ & $\begin{array}{l}\text { Hands ESC } \\
\text { yellow zone }\end{array}$ & $\begin{array}{l}\text { Hands ESC } \\
\text { green zone }\end{array}$ & $\begin{array}{l}\text { Feet ESC } \\
\text { red zone }\end{array}$ & $\begin{array}{c}\text { Feet ESC } \\
\text { yellow zone }\end{array}$ & $\begin{array}{c}\text { Feet ESC } \\
\text { green zone }\end{array}$ \\
\hline Caucasian & $0-40$ & $40-60$ & $60-100$ & $0-50$ & $50-70$ & $70-100$ \\
\hline African-American Ancestry & $0-30$ & $30-50$ & $50-100$ & $0-40$ & $40-60$ & $60-100$ \\
\hline Asian, Indian & $0-40$ & $40-60$ & $60-100$ & $0-40$ & $40-60$ & $60-100$ \\
\hline
\end{tabular}

All numeric values in micoSiemens $(\mu S)$.

Data from Casellini, Gordon Smith, and Freedman (9, 34, 43).

morbidity and mortality but also complicating the therapeutic care of comorbidities of elderly patients, e.g., the use of sympatholytic drugs and diuretics for hypertension or the optimization of glucose control for diabetes (45). Extensive research indicates that both sympathetic and parasympathetic dysfunction occur with age, with tonic vagal modulation decreasing and a relative or absolute increase in sympathetic tone $(46,47)$. Schmidt notes that neurons in the aging sympathetic ganglia are mostly intact, whereas dendrites, axons, and synapses can be severely abnormal and very likely contribute to faulty signaling (45).
It must be noted, however, that the degree of autonomic dysfunction in the elderly can be highly dependent on fitness level, obesity, and to a lesser extent gender (48-50). Our data on ESC only show a reduction in this function in the 8th decade (Table 4).

Some studies have indicated decreased sweat volumes on the dorsum of the hands and feet with aging (51), while Low found significant decreases in quantitative sudomotor axon reflex test (QSART) only in the lower extremities (52). In an earlier publication, Low had saliently concluded that age-related changes of the ANS vary with "the system tested, the site examined, and 
the particular test used" (53). We contend that ESC reflects not only sweating but somatic neurologic function which declines with age (54).

Sudoscan $^{\mathrm{TM}}$ examines the palms and soles, and measures an electrochemical response from the skin rather than a sweat volume or latency of response. As such, ESC results across ages 21-80 in healthy individuals have been found to remain fairly constant, and certainly permit use of a uniform set of diagnostic thresholds. This in turn allows identification of sudomotor dysfunction in older adults equally as easily as in younger ones (Table 4).

\section{ESC as a Tool to Measure Progression and Regression of Disease}

One of the most difficult and frustrating tasks in peripheral neuropathy has been to measure disease progression and response to therapeutic intervention with an easy, objective, and accurate tool. Knowing that salvaging large nerve fibers is practically impossible, the Holy Grail is to detect early nerve damage perhaps before metabolic parameters indicate any disease - and measure response or lack thereof accurately and quickly, allowing for treatment modification. Several research studies have now demonstrated that ESC may be a clinically meaningful tool in measuring neuropathy progression and regression.

In a cohort of 52 type 1 and 115 type 2 diabetic patients followed for 1 year, Calvet and colleagues (39) showed that a decrease in hand and foot ESC was observed in Type 2 patients treated without insulin, while a significant increase was observed in patients receiving insulin $(-3.8 \pm 9.7$ vs. $1.0 \pm 9.7 \mu \mathrm{S}, p=0.02$ for the hands and $-2.2 \pm 7.5$ vs. $4.1 \pm 8.8 \mu \mathrm{S}, p<0.001$ for the feet). Type 1 patients, all on insulin, had a non-significant increase in their feet ESC as well $(1.0 \pm 7.2 \mu S)$. During this period, none of the cohorts (insulin/no insulin) had any significant change in their glycemic control which would signal a need for therapeutic adjustment (delta $\mathrm{HbA} 1 \mathrm{c} 0.07 \pm 0.60 \%$ and $0.13 \pm 0.87 \%$, respectively); yet, clearly the no insulin group was experiencing ongoing peripheral nerve loss. This lack of relationship with glycemic control argues in favor of an effect of insulin per se on $\mathrm{Cl}^{-}$ion transport. Insulin is known to enhance the activity of $\mathrm{Na}^{+}-\mathrm{K}^{+}-2 \mathrm{Cl}^{-}$co-transporter (NKCC). Recently, Sun and colleagues demonstrated that insulin treatment remarkably enhanced the forskolin-stimulated $\mathrm{Cl}^{-}$secretion in epithelial A6 cells, which was associated with an increase in apical $\mathrm{Cl}^{-}$conductance by upregulating mRNA expression of both CFTR and NKCC (55). It would be of interest to examine the direct effects of euglycemic insulin administration as well as insulinotropic drugs on ESC quantification of $\mathrm{Cl}$ transport. Furthermore, sudorimetry may well prove useful in the evaluation of hyperinsulinemic insulin resistant states.

Conversely, Raisanen and colleagues (56) demonstrated that therapeutic intervention could improve small fiber function, and is easily measured using ESC. Residents of Tornio, Finland, who were at high cardiometabolic risk (BMI $>35 \mathrm{~kg} / \mathrm{m}^{2}$, very low $\mathrm{VO}_{2} \mathrm{max}$, diabetes, or heart disease), completed a supervised health promotion program for 12 months. Among 154 female participants with the lowest fitness level at baseline, those performing the highest level of weekly activity showed the greatest improvement in ESC scores, which was more pronounced than the changes in weight, waist circumference, or $\mathrm{VO}_{2} \max$ (Table 6). Raisanen's results confirm previous findings by Smith et al. (57) that small C-fibers damaged by metabolic stress can recover from simple lifestyle interventions lending further support to the notion that sudorimetry detects small somatic nerve fiber function that do not necessarily innervate sweat glands.

These studies indicate that ESC may provide information on the metabolic health of a patient, in particular on their small nerves, which may not otherwise be known to or measurable by the physician. Initial ESC results may be used to alter management and repeat testing after intervention may accurately measure whether the treatment is effective or if further changes are necessary. Significantly, the test is easy and precise enough to be clinically useful and meaningful for everyday outpatient practices.

One often neglected aspect of peripheral neuropathy is its impact on the patient's quality of life. Excellent tools such as the Norfolk Quality of Life-Diabetic Neuropathy (QOL-DN) have been developed to measure the patient's experience of diabetic neuropathy. The nerve fiber-specific domains of QOL$\mathrm{DN}$, in particular, have been shown to correlate with objective measures of nerve function (58-60). QOL-DN has also been shown to be a reliable indicator of the impact on QOL of symptomatic peripheral neuropathy experienced by patients with

TABLE 6 | Change between baseline and 12-month follow-up in weight, waist, $\mathrm{VO}_{2}$ max, and ESC risk score value in 154 women included in a lifestyle intervention program (56).

\begin{tabular}{|c|c|c|c|c|c|c|c|}
\hline & \multicolumn{2}{|c|}{$\begin{array}{l}\text { Without follow-up } \\
\text { of training level }(n=72)\end{array}$} & \multicolumn{2}{|c|}{$\begin{array}{c}\text { Low weekly } \\
\text { activity }^{\text {a }}(n=62)\end{array}$} & \multicolumn{2}{|c|}{$\begin{array}{c}\text { High weekly } \\
\text { activity }^{\text {b }}(n=20)\end{array}$} & \multirow[t]{2}{*}{$p$} \\
\hline & Mean & SD & Mean & SD & Mean & SD & \\
\hline Change in weight $(\mathrm{kg})$ & -0.9 & 3.4 & -1.6 & 4.0 & -3.3 & 4.8 & NS \\
\hline Change in waist $(\mathrm{cm})$ & -2.1 & 4.7 & -2.4 & 4.5 & -3.6 & 5.9 & NS \\
\hline Change in estimated $\mathrm{VO}_{2} \max$ (METs) & +0.5 & 0.9 & +0.8 & 0.9 & +1.1 & 1.2 & NS \\
\hline Change in hand ESC $(\mu S)$ & +5.0 & 8.4 & +3.0 & 9.4 & +8.4 & 12.3 & 0.043 \\
\hline Change in foot ESC $(\mu \mathrm{S})$ & +5.6 & 8.9 & +4.9 & 8.9 & +10.8 & 12.8 & 0.024 \\
\hline Change in ESC risk score (\%) & -5.1 & 5.3 & -4.7 & 6.4 & -8.5 & 6.8 & 0.027 \\
\hline
\end{tabular}

a Less than 150 min of moderate activity and 75 min of high activity.

${ }^{b}$ More than 150 min of moderate activity or 75 min of high activity; moderate activity 3-7 METs; high activity $>7$ METs. 
A

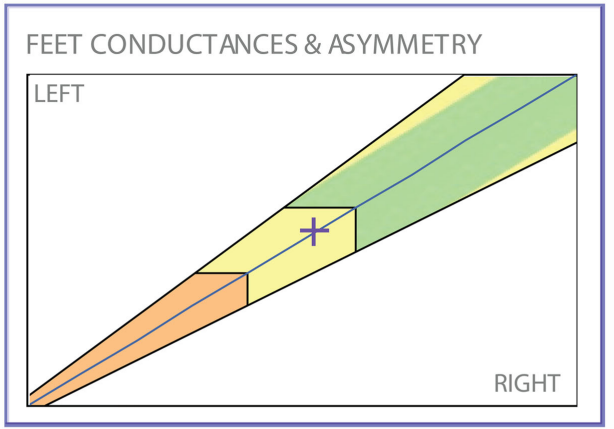

ANALYSIS:

Feet Mean ESC: $52 \mu \mathrm{S}$

Feet Mean Asymmetry: 1\%

Hands Mean ESC: $45 \mu \mathrm{S}$

Hands Mean Asymmetry: 4\%

B

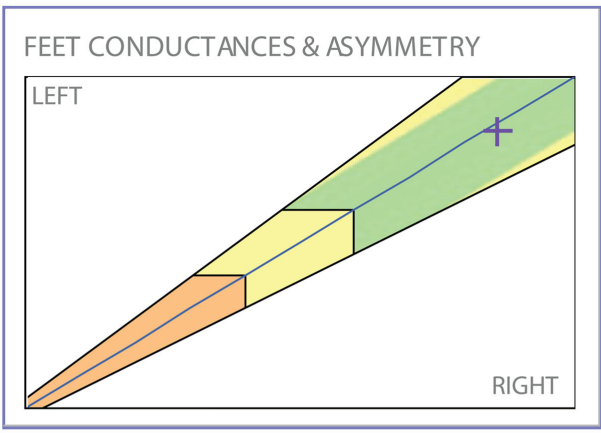

ANALYSIS:

Feet Mean ESC: $85 \mu \mathrm{S}$

Feet Mean Asymmetry: 2\%

Hands Mean ESC: $70 \mu \mathrm{S}$

Hands Mean Asymmetry: 0\%

Risk for cardiac autonomic neuropathy (investigation only): 15\%

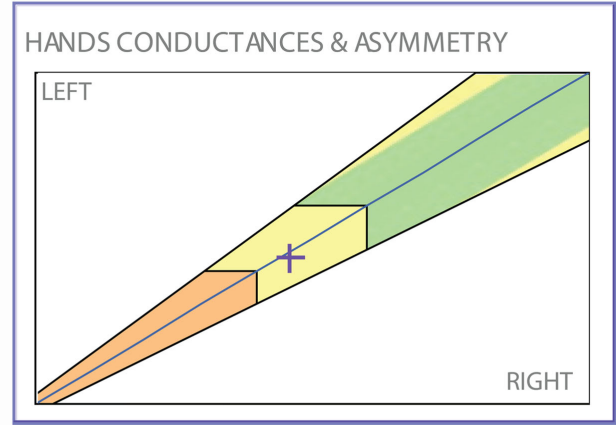

(Normalized ESC)

(No risk if $>60$, Elevated risk if $<40$, Moderate inbetween)

(Investigation suggested if $>20 \%$ )

(No risk if $>60$, Elevated risk if $<40$, Moderate inbetween)

(Investigation suggested if $>20 \%$ )

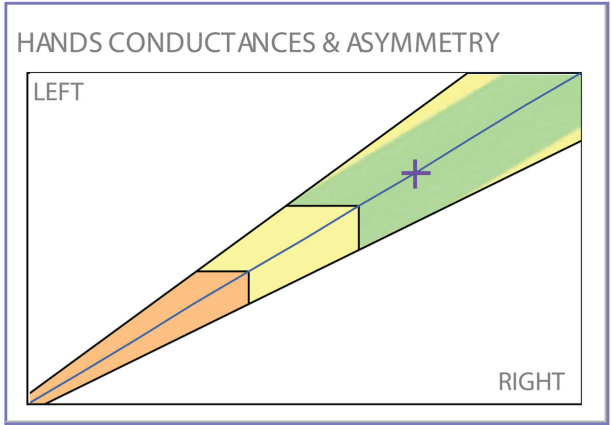

(Normalized ESC)

(No risk if $>60$, Elevated risk if $<40$, Moderate inbetween)

(Investigation suggested if $>20 \%$ )

(No risk if $>60$, Elevated risk if $<40$, Moderate inbetween)

(Investigation suggested if $>20 \%$ )

(Investigation suggested if $>50 \%$ )

FIGURE 4 | (A) ESC report dated October 19, 2012. (B) ESC report dated March 6, 2014.

V30M Transthyretin Familial Amyloid Polyneuropathy (TTRFAP) (61) In the Tafamadis study, Coelho and colleagues $(62,63)$ demonstrated that treatment of patients with TTR-FAP was associated with an improvement of Norfolk QOL scores of symptoms and activities of daily living in parallel with improved NIS-LL, supporting the notion that the QOL tool can be nerve fiber specific. Concurrently, early studies have shown that ESC is able to clearly discriminate the degree of small nerve fiber dysfunction in symptomatic vs. asymptomatic TTR-FAP (mean feet ESC: $42 \pm 27$ vs. $81 \pm 10 \mu \mathrm{S} ; p<0.0001$, respectively) (unpublished data). The next obvious step would be to measure the impact that ESC and QOL-DN together could have on disease staging and management in FAP, diabetes mellitus, and other small fiber neuropathies.

\section{Conclusion}

Small nerve fibers are starting to be recognized as valuable neuronal structures in the investigation of neuropathic diseases. They are thin, poorly myelinated, or unmyelinated, and therefore prone to destruction early in many pathological processes and often symptomatically debilitating. Indeed, the earliest changes appear to occur in the lower back, forearm, and thenar eminence as shown using Contact Heat Evoked Potential (CHEPS) (64), challenging the dogma that neuropathy is a distal to proximal disorder. Small nerves can be assessed objectively, and recognition of early dysfunction can allow intervention, treatment, and potentially cure. Though skin biopsy with IENFD is currently recognized as 

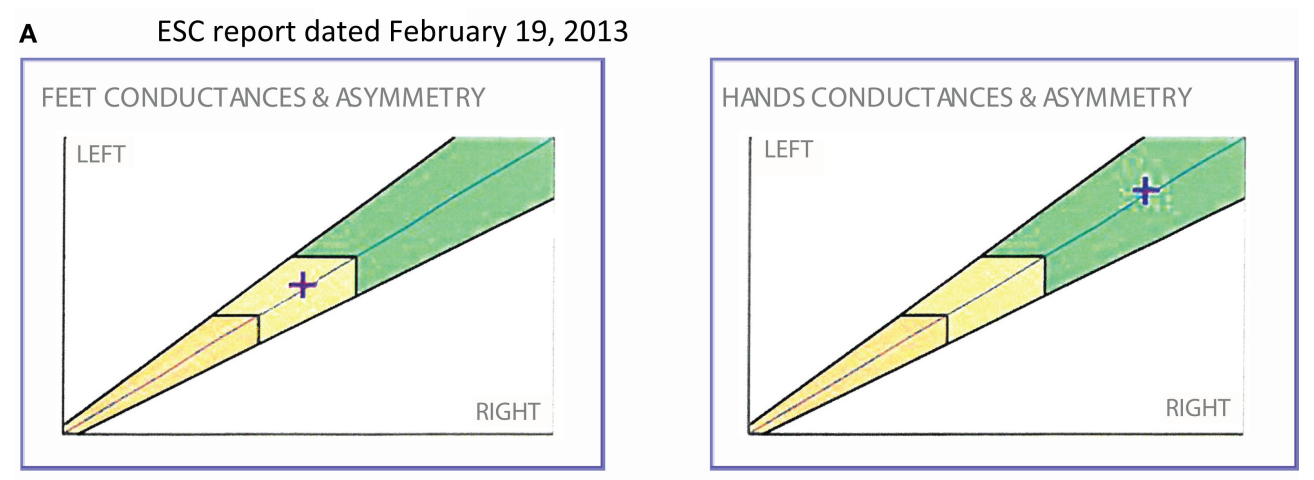

ANALYSIS:

Feet Mean ESC: $50 \mu \mathrm{S}$

Feet Mean Asymmetry: 0\%

Hands Mean ESC: $80 \mu \mathrm{S}$

Hands Mean Asymmetry: 2\%

B $\quad$ ESC report dated March 6, 2014

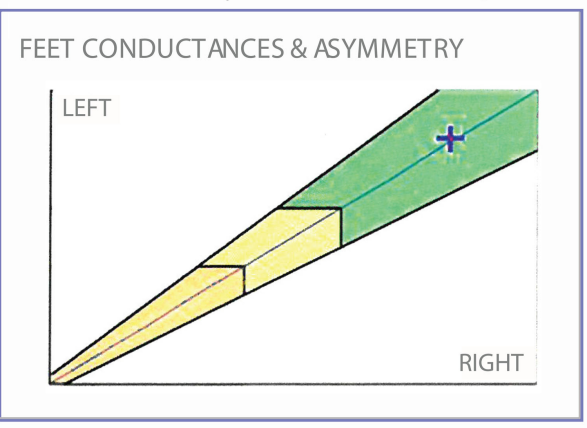

ANALYSIS:

Feet Mean ESC: $76 \mu \mathrm{S}$

Feet Mean Asymmetry: 1\%

Hands Mean ESC: $67 \mu \mathrm{S}$

Hands Mean Asymmetry: 1\%
(Normalized ESC)

(No risk if $>60$, Elevated risk if $<40$, Moderate inbetween)

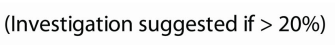

(No risk if $>60$, Elevated risk if $<40$, Moderate inbetween)

(Investigation suggested if $>20 \%$ )

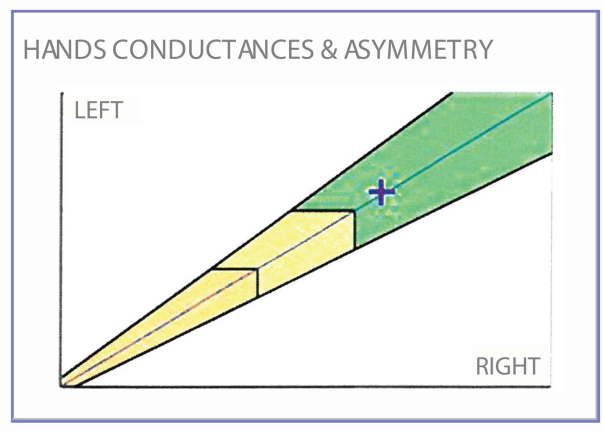

(Normalized ESC)

(No risk if $>60$, Elevated risk if $<40$, Moderate inbetween)

(Investigation suggested if $>20 \%$ )

(No risk if $>60$, Elevated risk if $<40$, Moderate inbetween)

(Investigation suggested if $>20 \%$ )

FIGURE 5 | (A) ESC report dated February 19, 2013. (B) ESC report dated March 6, 2014.

the gold standard in the evaluation of small fibers, sudorimetry technology has evolved dramatically; appears to be a rapid, noninvasive, robust, and accurate biomarker for small fibers; and can easily be integrated into clinical practice. Disease detection, progression, and response to therapy have been shown to be measurable with ESC, and it may eventually assist the physician in monitoring more challenging disorders like CIDP. To allow for global evaluation of sudomotor function, however, the technology would need to be expanded in order to obtain information on dermatomes across the entire body.

\section{Case Vignettes on the Clinical Utility of Sudorimetry}

Prior studies demonstrate that ESC technology is able to rapidly and precisely measure the effects of a therapeutic intervention; furthermore, individual patient examples are suggesting similar results. Below are two patients whose small nerve fiber function was uniquely measurable by sudorimetry.

\section{Vignette 1}

The patient is a 47-year-old woman with well-controlled type 1 diabetes (HbAlc 6.4-7.5\%) and 8+ years of painful diabetic neuropathy and gastroparesis. ESC measurements (Figure 4A) and cardiac autonomic functions were abnormal: heart rate variability response to expiration/inspiration (E/I), Valsalva maneuver, and the ratio of the $\mathrm{RR}$ interval for the 30th to the 15 th beat upon standing were 1.05, 1.10, and 1.06, respectively. Gastroparesis was confirmed by a gastric emptying study and required a combination of psyllium fiber, metoclopramide, and erythromycin EES. Alpha lipoic acid (ALA) $600 \mathrm{mg}$ po bid was prescribed. Ten months later, the patient returned with normalized ESC 
results (Figure 4B), complete resolution of the gastroparesis, but unchanged peripheral neuropathy symptoms, autonomic functions (E/I, Valsalva, and 30:15 ratios 1.10, 1.08, 1.08, respectively), and $\mathrm{HbAlc}$.

Past research has suggested that ALA may benefit diabetic neuropathy, but objective quantification of its therapeutic effects has been difficult (65). The authors of a 2012 meta-analysis of ALA trials confirmed that 3 weeks of intravenous ALA results in significant and clinically relevant reductions in neuropathic pain (66) but declared that it was unclear if significant improvements measured for oral ALA were clinically relevant. Mijnhout et al., though, based their conclusions on the evolution of a single outcome measure, namely a $\geq 30 \%$ change in Total Symptom Score (TSS). The NATHAN 1 study, comparing $600 \mathrm{mg}$ daily oral ALA vs. placebo, did not meet its primary endpoint (NIS-LL plus 7 neurophysiologic tests), despite 4 years of follow-up. However, Neuropathy Impairment Score, NIS-LL, and Neuropathy Symptoms and Change (NSC) score improved with ALA (67). NATHAN 1 firmly demonstrated that diabetic neuropathy, especially nerve conduction deficits, progresses quite slowly and that it may be more sensible to measure improvements in the treatment arm of a study rather than deficit progression in the placebo arm. ESC measurement was able to demonstrate improvements in small fibers with use of ALA in this patient; the ESC normalization correlated with resolution of her gastroparesis and opens the door

\section{References}

1. Young LH, Wackers FJ, Chyun DA, Davey JA, Barrett EJ, Taillefer R, et al. Cardiac outcomes after screening for asymptomatic coronary artery disease in patients with type 2 diabetes: the DIAD study: a randomized controlled trial. JAMA (2009) 301:1547-55. doi:10.1001/jama.2009.476

2. Pop-Busui R, Evans G, Gerstein H, Fonseca V, Fleg J, Hoogwerf B, et al. Effects of cardiac autonomic dysfunction on mortality risk in the action to control cardiovascular risk in diabetes (ACCORD) trial. Diabetes Care (2010) 33:1578-84. doi:10.2337/dc10-0125

3. Pop-Busui R. Cardiac autonomic neuropathy in diabetes: a clinical perspective. Diabetes Care (2010) 33:434-41. doi:10.2337/dc09-1294

4. Wulsin LR, Horn PS, Perry JL, Massaro J, D’Agostino R. Autonomic imbalance as a predictor of metabolic risks, cardiovascular disease, diabetes, and mortality autonomic imbalance predicts CVD, DM, mortality. J Clin Endocrinol Metab (2015). doi:10.1210/jc.2014-4123

5. Maser RE, Mitchell BD, Vinik AI, Freeman R. The association between cardiovascular autonomic neuropathy and mortality in individuals with diabetes: a meta-analysis. Diabetes Care (2003) 26:1895-901. doi:10.2337/diacare.26.6. 1895

6. Vinik A, Maser R, Ziegler D. Autonomic imbalance: prophet of doom or scope for hope? Diabet Med (2011) 28:643-51. doi:10.1111/j.1464-5491. 2010.03184.x

7. Dyck PJ, Melton LJ III, O’Brien PC, Service FJ. Approaches to improve epidemiological studies of diabetic neuropathy: insights from the Rochester Diabetic Neuropathy Study. Diabetes (1997) 46(Suppl 2):S5-8. doi:10.2337/diab.46.2.S5

8. Casellini CM, Barlow PM, Rice AL, Casey M, Simmons K, Pittenger G, et al. A 6-month, randomized, double-masked, placebo-controlled study evaluating the effects of the protein kinase $\mathrm{C}$-\{beta\} inhibitor ruboxistaurin on skin microvascular blood flow and other measures of diabetic peripheral neuropathy. Diabetes Care (2007) 30:896-902. doi:10.2337/dc06-1699

9. Smith AG, Lessard M, Reyna S, Doudova M, Singleton JR. The diagnostic utility of Sudoscan for distal symmetric peripheral neuropathy. J Diabetes Complications (2014) 28:511-6. doi:10.1016/j.jdiacomp.2014.02.013

10. Feldman EL, Stevens MJ, Thomas PK, Brown MB, Canal N, Greene DA. A practical two-step quantitative clinical and electrophysiological assessment for the to further investigate ESC's utility in measuring pharmacological intervention in autonomic neuropathy.

\section{Vignette 2}

The patient is a 50 -year-old male with type 2 diabetes and a BMI of 30 . He had been treated with metformin for several years and was optimally controlled. He denied any symptom of neuropathy; yet, ESC measurements demonstrated moderate sudomotor function loss (Figure 5A). A vitamin B12 level drawn that day was low $(<150 \mathrm{pg} / \mathrm{mL})$. He was started on vitamin $\mathrm{B} 12$ replacement and continued metformin. A repeat ESC 3 months later showed recovery of feet ESC scores (Figure 5B).

It has now been established that vitamin B12 threshold levels leading to impairment of nerve function is around $260 \mathrm{pmol} / \mathrm{L}$ $(70 \mathrm{pg} / \mathrm{ml})$ as shown in the Health ABC study (68). This case illustrates not only ESC's ability to measure therapeutic response, but also its diagnostic capacity to detect a (possibly iatrogenic) neuropathy prior to symptomatology and identity candidates on metformin for B12 replacement. Fonseca and colleagues were unable to show that 24 weeks of treatment with a combination of methylcobalamin, methylfolate, and pyridoxal phosphate could alter vibration detection despite improving symptoms of neuropathy as well as quality of life $(69,70)$. Their study findings support the possible role of an objective measure like ESC in this clinical setting.

diagnosis and staging of diabetic neuropathy. Diabetes Care (1994) 17:1281-9. doi:10.2337/diacare.17.11.1281

11. Perkins B, Bril V. Electrophysiologic testing in diabetic neuropathy. Handb Clin Neurol (2014) 126:235-48. doi:10.1016/B978-0-444-53480-4.00018-7

12. Vinik AI, Bril V, Litchy WJ, Price KL, Bastyr EJ III, MBBQ Study Group. Sural sensory action potential identifies diabetic peripheral neuropathy responders to therapy. Muscle Nerve (2005) 32(5):619-25. doi:10.1002/mus.20423

13. Tesfaye S, Vileikyte L, Rayman G, Sindrup S, Perkins B, Baconja M, et al. Painful diabetic peripheral neuropathy: consensus recommendations on diagnosis, assessment and management. Diabetes Metab Res Rev (2011) 27:629-38. doi:10.1002/dmrr.1225

14. Vinik AI, Ziegler D. Diabetic cardiovascular autonomic neuropathy. Circulation (2007) 115:387-97. doi:10.1161/CIRCULATIONAHA.106.634949

15. Colombo J, Arora R, DePace N, Vinik AI. Chapter 12. The progression of autonomic dysfunction in chronic disease. Clinical Autonomic Dysfunction: Measurement, Indication, Therapies, and Outcomes. Springer International Publishing Switzerland (2015). p. 139-49. doi:10.1007/978-3-319-07371-2

16. Pittenger GL, Ray M, Burcus NI, McNulty P, Basta B, Vinik AI. Intraepidermal nerve fibers are indicators of small-fiber neuropathy in both diabetic and nondiabetic patients. Diabetes Care (2004) 27:1974-9. doi:10.2337/diacare.27. 8.1974

17. Vinik AI, Nevoret M, Casellini C, Parson H. Neurovascular function and sudorimetry in health and disease. Curr Diab Rep (2013) 13:517-32. doi:10. 1007/s11892-013-0392-x

18. Boden G, Hoeldtke RD. Nerves, fat, and insulin resistance. N Engl J Med (2003) 349:1966-7. doi:10.1056/NEJMcibr035229

19. Illigens BM, Gibbons $\mathrm{CH}$. Sweat testing to evaluate autonomic function. Clin Auton Res (2009) 19:79-87. doi:10.1007/s10286-008-0506-8

20. Gibbons CH, Illigens BM, Wang N, Freeman R. Quantification of sweat gland innervation: a clinical-pathologic correlation. Neurology (2009) 72:1479-86. doi:10.1212/WNL.0b013e3181a2e8b8

21. Wang N, Gibbons CH. Skin biopsies in the assessment of the autonomic nervous system. Handb Clin Neurol (2013) 117:371-8. doi:10.1016/ B978-0-444-53491-0.00030-4

22. Freeman R, Chapleau MW. Testing the autonomic nervous system. Handb Clin Neurol (2013) 115:115-36. doi:10.1016/B978-0-444-52902-2.00007-2 
23. Sumner C, Sheth S, Griffin J, Cornblath D, Polydefkis M. The spectrum of neuropathy in diabetes and impaired glucose tolerance. Neurology (2003) 60(1):108-11. doi:10.1212/WNL.60.1.108

24. Pittenger G, Mehrabyan A, Simmons K, Rice A, Dublin C, Barlow P, et al. Small fiber neuropathy is associated with the metabolic syndrome. Metab Syndr Relat Disord (2005) 3:113-21. doi:10.1089/met.2005.3.113

25. Tavee J, Zhou L. Small fiber neuropathy: a burning problem. Cleve Clin J Med (2009) 76:297-305. doi:10.3949/ccjm.76a.08070

26. Themistocleous AC, Ramirez JD, Serra J, Bennett DL. The clinical approach to small fibre neuropathy and painful channelopathy. Pract Neurol (2014) 14:368-79. doi:10.1136/practneurol-2013-000758

27. Boger MS, Hulgan T, Haas DW, Mitchell V, Smith AG, Singleton JR, et al. Measures of small-fiber neuropathy in HIV infection. Auton Neurosci (2012) 169:56-61. doi:10.1016/j.autneu.2012.04.001

28. Thaisetthawatkul P, Fernandes Filho JA, Herrmann DN. Contribution of QSART to the diagnosis of small fiber neuropathy. Muscle Nerve (2013) 48:883-8. doi:10.1002/mus.23891

29. Bilen H, Atmaca A, Akcay G. Neuropad indicator test for diagnosis of sudomotor dysfunction in type 2 diabetes. Adv Ther (2007) 24:1020-7. doi:10.1007/ BF02877707

30. Papanas N, Boulton AJ, Malik RA, Manes C, Schnell O, Spallone V, et al. A simple new non-invasive sweat indicator test for the diagnosis of diabetic neuropathy. Diabet Med (2013) 30:525-34. doi:10.1111/dme. 12000

31. Peltier A, Smith AG, Russell JW, Sheikh K, Bixby B, Howard J, et al. Reliability of quantitative sudomotor axon reflex testing and quantitative sensory testing in neuropathy of impaired glucose regulation. Muscle Nerve (2009) 39:529-35. doi: $10.1002 /$ mus. 21210

32. Berger MJ, Kimpinski K. Test-retest reliability of quantitative sudomotor axon reflex testing. J Clin Neurophysiol (2013) 30:308-12. doi:10.1097/WNP. 0b013e3182873254

33. Hilz MJ, Dutsch M. Quantitative studies of autonomic function. Muscle Nerve (2006) 33:6-20. doi:10.1002/mus.20365

34. Casellini CM, Parson HK, Richardson MS, Nevoret ML, Vinik AI. Sudoscan, a noninvasive tool for detecting diabetic small fiber neuropathy and autonomic dysfunction. Diabetes Technol Ther (2013) 15:948-53. doi:10.1089/dia.2013. 0129

35. Loavenbruck A, Wendelschaefer-Crabbe G, Sandroni P, Kennedy WR. Quantification of sweat gland volume and innervation in neuropathy: correlation with thermoregulatory sweat testing. Muscle Nerve (2014) 50:528-34. doi:10. $1002 /$ mus. 24185

36. Ishibashi F, Kojima R, Kawasaki A, Yamanaka E, Kosaka A, Uetake H. Correlation between sudomotor function, sweat gland duct size and corneal nerve fiber pathology in patients with type 2 diabetes mellitus. J Diabetes Investig (2014) 5:588-96. doi:10.1111/jdi.12171

37. Yajnik CS, Kantikar V, Pande A, Deslypere JP, Dupin J, Calvet JH, et al. Screening of cardiovascular autonomic neuropathy in patients with diabetes using non-invasive quick and simple assessment of sudomotor function. Diabetes Metab (2013) 39:126-31. doi:10.1016/j.diabet.2012.09.004

38. Gin H, Baudoin R, Raffaitin CH, Rigalleau V, Gonzalez C. Non-invasive and quantitative assessment of sudomotor function for peripheral diabetic neuropathy evaluation. Diabetes Metab (2011) 37:527-32. doi:10.1016/j.diabet. 2011.05.003

39. Calvet JH, Dupin J, Winiecki H, Schwarz PE. Assessment of small fiber neuropathy through a quick, simple and non invasive method in a German diabetes outpatient clinic. Exp Clin Endocrinol Diabetes (2013) 121:80-3. doi:10.1055/ s-0032-1323777

40. Ecker PM, Lin CC, Powers J, Kobilka BK, Dubin AM, Bernstein D. Effect of targeted deletions of beta1- and beta2-adrenergic-receptor subtypes on heart rate variability. Am J Physiol Heart Circ Physiol (2006) 290:H192-9. doi:10.1152/ ajpheart.00032.2005

41. Eranki VG, Santosh R, Rajitha K, Pillai A, Sowmya P, Dupin J, et al. Sudomotor function assessment as a screening tool for microvascular complications in type 2 diabetes. Diabetes Res Clin Pract (2013) 101(3):e11-3. doi:10.1016/j.diabres. 2013.07.003

42. Ozaki R, Cheung KKT, Wu E, Kong A, Yang X, Lau E, et al. Chan JCN. A new tool to detect kidney disease in Chinese type 2 diabetes patients - comparison of EZSCAN with standard screening methods. Diabetes Technol Ther (2011) 13(9):937-43. doi:10.1089/dia.2011.0023
43. Freedman BI, Bowden DW, Smith SC, Xu J, Divers J. Relationships between electrochemical skin conductance and kidney disease in Type 2 diabetes. J Diabetes Complications (2014) 28:56-60. doi:10.1016/j.jdiacomp.2013.09.006

44. Schwarz P, Brunswick P, Calvet J-H. EZSCAN a new technology to detect diabetes risk. Br J Diabet Vasc Dis (2011) 11:204-9. doi:10.1177/1474651411402629

45. Schmidt RE. Age-related sympathetic autonomic neuropathology. In: Kuchel GA, Hof PR, editors. Autonomic Nervous System in Old Age. Interdiscipl Top Gerontol. Basel: Karger (2004). p. 1-23.

46. Petrofsky J, Berk L, Al-Nakhli H. The influence of autonomic dysfunction associated with aging and type 2 diabetes on daily life activities. Exp Diabetes Res (2012) 2012:657103. doi:10.1155/2012/657103

47. Hotta H, Uchida S. Aging of the autonomic nervous system and possible improvements in autonomic activity using somatic afferent stimulation. Geriatr Gerontol Int (2010) 10(Suppl 1):S127-36. doi:10.1111/j.1447-0594.2010. 00592.x

48. Seals DR, Monahan KD, Bell C, Tanaka H, Jones PP. The aging cardiovascular system: changes in autonomic function at rest and in response to exercise. Int $J$ Sport Nutr Exerc Metab (2001) 11(Suppl):S189-95.

49. Abhishekh HA, Nisarga P, Kisan R, Meghana A, Chandran S, Trichur R, et al. Influence of age and gender on autonomic regulation of heart. J Clin Monit Comput (2013) 27:259-64. doi:10.1007/s10877-012-9424-3

50. Alvarez GE, Davy BM, Ballard TP, Beske SD, Davy KP. Weight loss increases cardiovagal baroreflex function in obese young and older men. Am J Physiol Endocrinol Metab (2005) 289:E665-9. doi:10.1152/ajpendo.00487.2004

51. Ferrer T, Ramos MJ, Perez-Sales P, Perez-Jimenez A, Alvarez E. Sympathetic sudomotor function and aging. Muscle Nerve (1995) 18:395-401. doi:10.1002/ mus. 880180405

52. Low PA, Denq JC, Opfer-Gehrking TL, Dyck PJ, O’Brien PC, Slezak JM. Effect of age and gender on sudomotor and cardiovagal function and blood pressure response to tilt in normal subjects. Muscle Nerve (1997) 20:1561-8. doi:10.1002/ (SICI) 1097-4598(199712)20:12<1561::AID-MUS11>3.0.CO;2-3

53. Low PA, Opfer-Gehrking TL, Proper CJ, Zimmerman I. The effect of aging on cardiac autonomic and postganglionic sudomotor function. Muscle Nerve (1990) 13:152-7. doi:10.1002/mus.880130212

54. Vinik AI, Strotmeyer ES, Nakave AA, Patel CV. Diabetic neuropathy in older adults. Clin Geriatr Med (2008) 24:407-35. doi:10.1016/j.cger.2008.03.011

55. Sun H, Niisato N, Inui T, Marunaka Y. Insulin is involved in transcriptional regulation of NKCC and the CFTR $\mathrm{Cl}(-)$ channel through PI3K activation and ERK inactivation in renal epithelial cells. J Physiol Sci (2014) 64:433-43. doi:10.1007/s12576-014-0338-3

56. Raisanen A, Eklund J, Calvet J-H, Tuomilehto J. Sudomotor function as a tool for cardiorespiratory fitness level evaluation: comparison with VO2 max. Int J Environ Res Public Health (2014) 11:5839-48. doi:10.3390/ijerph110605839

57. Smith AG, Russell J, Feldman EL, Goldstein J, Peltier A, Smith S, et al. Lifestyle intervention for pre-diabetic neuropathy. Diabetes Care (2006) 29:1294-9. doi: $10.2337 / \mathrm{dc} 06-0224$

58. Vinik EJ, Hayes RP, Oglesby A, Bastyr E, Barlow P, Ford-Molvik SL, et al. The development and validation of the Norfolk QOL-DN, a new measure of patients' perception of the effects of diabetes and diabetic neuropathy. Diabetes Technol Ther (2005) 7:497-508. doi:10.1089/dia.2005.7.497

59. Vinik EJ, Hayes C, Oglesby A, Vinik AI. Identification of factors in the nerve fiber specific quality of life(QOL-DN) inventory that reflect QOL and health status. Diabetes (2004) 53:A295.

60. Vinik E, Paulson J, Ford-Molvik S, Vinik A. German-translated norfolk quality of life (QOL-DN) identifies the same factors as the english version of the tool and discriminates different levels of neuropathy severity. J Diabetes Sci Technol (2008) 2:1075-86. doi:10.1177/193229680800200616

61. Vinik EJ, Vinik AI, Paulson JF, Merkies IS, Packman J, Grogan DR, et al. Norfolk QOL-DN: validation of a patient reported outcome measure in transthyretin familial amyloid polyneuropathy. J Peripher Nerv Syst (2014) 19:104-14. doi:10. 1111/jns5.12059

62. Coelho T, Maia LF, Martins da Silva A, Waddington CM, Plante-Bordeneuve V, Lozeron $\mathrm{P}$, et al. Tafamidis for transthyretin familial amyloid polyneuropathy: a randomized, controlled trial. Neurology (2012) 79:785-92. doi:10.1212/WNL. 0b013e3182661eb1

63. Coelho T, Maia LF, da Silva AM, Cruz MW, Plante-Bordeneuve V, Suhr $\mathrm{OB}$, et al. Long-term effects of tafamidis for the treatment of transthyretin familial amyloid polyneuropathy. J Neurol (2013) 260:2802-14. doi:10.1007/ s00415-013-7051-7 
64. Parson HK, Nguyen VT, Orciga MA, Boyd AL, Casellini CM, Vinik AI. Contact heat-evoked potential stimulation for the evaluation of small nerve fiber function. Diabetes Technol Ther (2013) 15:150-7. doi:10.1089/dia.2012.0202

65. Ziegler D, Nowak H, Kempler P, Vargha P, Low PA. Treatment of symptomatic diabetic polyneuropathy with the antioxidant alpha-lipoic acid: a meta-analysis. Diabet Med (2004) 21:114-21. doi:10.1111/j.1464-5491.2004.01109.x

66. Mijnhout GS, Kollen BJ, Alkhalaf A, Kleefstra N, Bilo HJ. Alpha lipoic acid for symptomatic peripheral neuropathy in patients with diabetes: a meta-analysis of randomized controlled trials. Int J Endocrinol (2012) 2012:456279. doi:10. $1155 / 2012 / 456279$

67. Ziegler D, Low PA, Litchy WJ, Boulton AJM, Vinik AI, Freeman R, et al. Efficacy and safety of antioxidant treatment with alpha-lipoic acid over 4 years in diabetic polyneuropathy. The NATHAN 1 trial. Diabetes Care (2011) 34:2054-60. doi: $10.2337 / \mathrm{dc} 11-0503$

68. Strotmeyer ES, de RN, Schwartz AV, Resnick HE, Goodpaster BH, Faulkner $\mathrm{KA}$, et al. Sensory and motor peripheral nerve function and lower-extremity quadriceps strength: the health, aging and body composition study. J Am Geriatr Soc (2009) 57:2004-10. doi:10.1111/j.1532-5415.2009.02487.x
69. Fonseca V, Lavery L, Thethi TK. Metanx in type 2 diabetes with peripheral neuropathy: a randomized trial. Am J Med (2013) 126:141-9. doi:10.1016/j. amjmed.2012.06.022

70. Vinik AI. A medicinal food provides food for thought in managing diabetic neuropathy. Am J Med (2013) 126:95-6. doi:10.1016/j.amjmed.2012.08.008

71. Cross SA. Pathophysiology of pain. Mayo Clin Proc (1994) 69(4):375-83.

Conflict of Interest Statement: The authors declare that the research was conducted in the absence of any commercial or financial relationships that could be construed as a potential conflict of interest.

Copyright (c) 2015 Vinik, Nevoret and Casellini. This is an open-access article distributed under the terms of the Creative Commons Attribution License (CC BY). The use, distribution or reproduction in other forums is permitted, provided the original author(s) or licensor are credited and that the original publication in this journal is cited, in accordance with accepted academic practice. No use, distribution or reproduction is permitted which does not comply with these terms. 